\title{
Green synthesis of metal nanoparticles from fruit extract with its antibacterial activity
}

\author{
Ashok Kr. Acharya \\ PG Department of chemistry Ranchi College, Ranchi, Jharkhand-834001 \\ Email: ashokacharya01@gmail.com
}

Synthesis of metal nanoparticles has received significant attention because of their antimicrobial [1], antibacterial [2], antioxidant capacity. Bio mimetic [3] approach was carried out during synthesis of silver nanoparticles. Bio-inspired methods are advantageous compared to other synthetic methods as they are economical and restrict the use of toxic chemicals as well as high pressure, energy and temperature. In recent time, several groups have been reported to achieve success in the synthesis of $\mathrm{Au}, \mathrm{Ag}, \& \mathrm{Pd}$ nanoparticles [4] from various parts of herbal plants.

In the present piece of work, aqueous extracts of citrus fruits were used as reducing and stabilising agent for the synthesis of $\mathrm{AgNp}$ using bio reduction method. The condition of formation of $\mathrm{AgNp}$ was established by varying concentration and $\mathrm{pH}$ of the mixture. At various temperature formation of Ag-NP were studied. After complete reduction, the sample was centrifuged at $12000 \mathrm{rpm}$ then heated and dried, followed by characterization by using UVVisible, X-RD and SEM techniques. Antibacterial activity of biogenic AgNPs was evaluated by using standard ZOI.

Table 1: Variation of $\lambda_{\max }$ with molar concentration

\begin{tabular}{|l|l|l|l|}
\hline $\begin{array}{l}\text { Sample } \\
\text { Number }\end{array}$ & $\begin{array}{l}\text { Molar } \\
\text { concentration } \\
\text { of } \mathrm{AgNO}_{3}\end{array}$ & $\begin{array}{l}\mathrm{pH} \\
\text { Value }\end{array}$ & $\lambda_{\max }$ \\
\hline 1 & $1 \times 10^{-3} \mathrm{M}$ & 5 & 425 \\
\hline 2 & $1.5 \times 10^{-3} \mathrm{M}$ & 6 & 418 \\
\hline 3 & $2 \times 10^{-3} \mathrm{M}$ & 6.5 & 407 \\
\hline
\end{tabular}

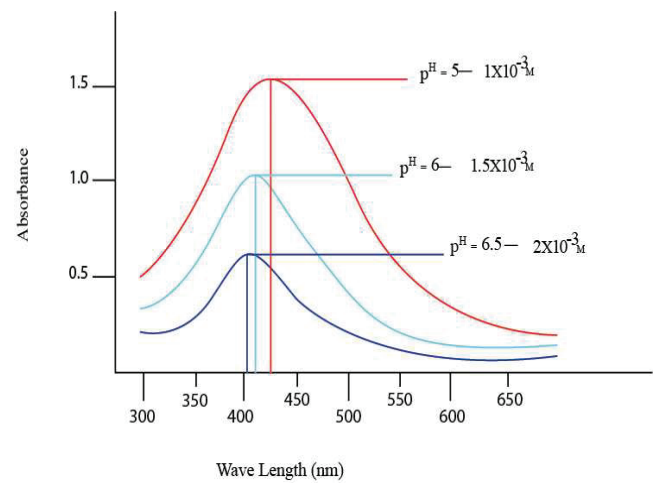

Figure 1: Absorbance of Ag-NPs Synthesized with different molar concentration of $\mathrm{AgNO}_{3}$ at room temperature

\section{References}

1. A. Sathya, V. Ambikapathy, Drug invent Today 4(8): (2012), 408-410.

2. N.M. Huang, H.N. Lim, S.Radiman, P.S. Khiew, Colloids and surfaces A:Physicochemical and Engineering Aspects Vol 35,(2010)69

3. T.C. Prathna, L.Mathew, N. Chandrasekaran, A.M. Raichur and A. Mukharjee, Biomimet Lear, Nature (2010),25-40.

4. Y.S. Jae and S.K. Beom, Bioprocess Biosyst.Eng., 32(2009),79-84 